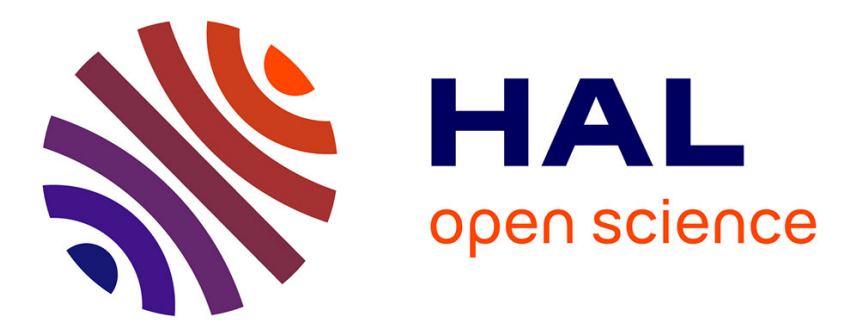

\title{
The Role of Tweet-Related Emotion on the Exhaustion - Recovery from Work Relationship
}

Konstantina Foti, Despoina Xanthopoulou, Savvas Papagiannidis, Konstantinos Kafetsios

\section{- To cite this version:}

Konstantina Foti, Despoina Xanthopoulou, Savvas Papagiannidis, Konstantinos Kafetsios. The Role of Tweet-Related Emotion on the Exhaustion - Recovery from Work Relationship. 18th Conference on e-Business, e-Services and e-Society (I3E), Sep 2019, Trondheim, Norway. pp.380-391, 10.1007/9783-030-29374-1_31. hal-02510156

\section{HAL Id: hal-02510156 \\ https://hal.inria.fr/hal-02510156}

Submitted on 17 Mar 2020

HAL is a multi-disciplinary open access archive for the deposit and dissemination of scientific research documents, whether they are published or not. The documents may come from teaching and research institutions in France or abroad, or from public or private research centers.
L'archive ouverte pluridisciplinaire HAL, est destinée au dépôt et à la diffusion de documents scientifiques de niveau recherche, publiés ou non, émanant des établissements d'enseignement et de recherche français ou étrangers, des laboratoires publics ou privés.

\section{(c)(1)}

Distributed under a Creative Commons Attribution| 4.0 International License 


\title{
The role of tweet-related emotion on the exhaustion - recovery from work relationship.
}

\author{
Konstantina Foti ${ }^{1}$, Despoina Xanthopoulou ${ }^{2}$, Savvas Papagiannidis ${ }^{1}$, Konstantinos \\ Kafetsios $^{3}$

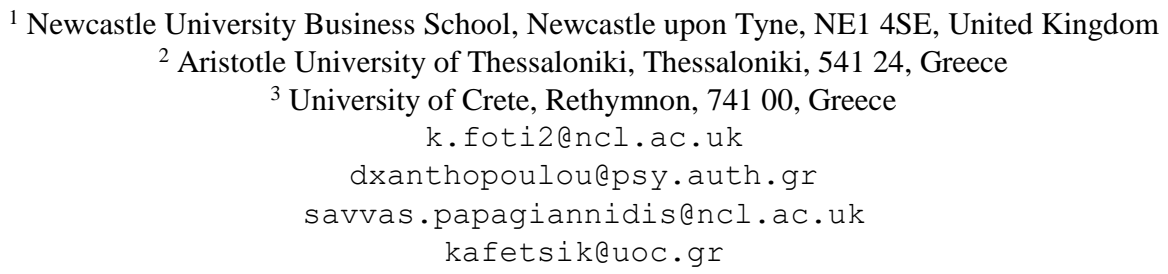

\begin{abstract}
This study examined the relationship between work-related exhaustion and the recovery experiences of psychological detachment and relaxation during leisure, and the moderating role of emotion (positive \& negative) when using Twitter during and after work. Participants were asked to rate their emotion based on the tweets they posted each day, together with their exhaustion at work and their recovery experiences at the end of the day. Results from the multilevel analyses showed that experiencing positive emotion when tweeting at work buffered the negative relationship of exhaustion and psychological detachment, but not relaxation. Negative emotion did not moderate the relationship significantly. The results show that social media can play a significant role in the recovery process and offer interesting insights both for employees and organisations.
\end{abstract}

Keywords: emotion, exhaustion, psychological detachment, relaxation, Twitter

\section{Introduction}

Employees deal with several demands on a daily basis at work. Research has shown that employees need to adequately unwind and recover from job demands daily as this prevents further energy depletion and keeps them physically and mentally healthy [1, 2]. So far, research examined how specific activity types (e.g. work-related, household, physical, social and low effort) associate with recovery. However, due to major changes introduced by the progress of Information and Communication Technologies (ICTs), many of the activities that employees engage in today are digital, take place online and relate to social media. Existing research on ICTs and recovery paid attention on the medium, such as smartphones [3], on the Internet use [4], or on social media use in general $[5,6]$, thus, neglecting the nature of the social media experience and its role on recovery. To address this gap in the literature, we examined active social media use and 
the impact the nature of the experience while using social media as a new context may have on the process of recovery from work. Specifically, we investigated the moderating role of emotion (positive \& negative) by tweets posted during and after work on the exhaustion-recovery experiences relationship. The study adds to the literature by integrating the role of social media in the recovery process. Importantly, we advance our understanding of the conditions under which social media use is more likely to be beneficial or detrimental for the daily recovery. By investigating the moderating role of emotion elicited by the social media activity, we bring out the conditions under which tweeting at work and during leisure may help (or impede) exhausted employees to detach from work and relax during their off-job time.

\section{Daily Exhaustion and Recovery from Work}

Recovery is the process where employees unwind and refill the resources used at work [7]. Following the effort-recovery model [8], investing effort to deal with job demands leads to physio-psychological activation and acute responses, such as exhaustion (i.e., the state of energy depletion from job demands) [9]. Hence, employees recover when demands are no longer present, which allows for their physio-psychological systems to return to baseline. In this context, recovery can occur by taking breaks between work tasks (i.e., internal), and at leisure time (i.e., external).

Engaging in off-job activities that enable recovery experiences, employees can "recharge their batteries" and feel recovered [10-13]. This is because recovery experiences facilitate replenishing those resources that employees invested at work and even gain additional resources [14]. From the four recovery experiences (i.e. psychological detachment, relaxation, control \& mastery) [7], this study focuses on psychological detachment and relaxation, that are considered the most central. Psychological detachment refers to switching off from work, while relaxation is a state of low activation [7].

Exhaustion was found to correlate negatively to psychological detachment and relaxation [7]. Also, exhausted employees were less likely to detach psychologically from work [2]. When feeling exhausted, employees are unable to meet job demands due to lack of energy and as such they fail to meet performance goals [15]. As a result, exhausted employees are more likely to continue working during leisure [16] to compensate for performance failures and as such, they are less likely to detach from work and relax. Also, exhausted employees are less likely to relax during their leisure time. Exhaustion due to prolonged exposure to work stressors exposes employees to extended activation of their functional systems [8]. At the same time, resource depletion due to exhaustion impedes employees from investing resources in activities that can help them experience relaxation and recover $[7,17]$.

Hypothesis 1: Exhaustion is negatively associated with psychological detachment and relaxation during leisure. 


\section{Social Media and the Recovery Process}

The rapid growth of social media has introduced major changes in everyday life. Social media refer to "web-based services that allow individuals, communities, and organizations to collaborate, connect, interact, and build community by enabling them to create, co-create, modify, share, and engage with user-generated content that is easily accessible" [18]. Today, there are approximately three billion people globally logging onto social media, spending an average of two hours per day [19]. Research so far has presented social media as a double-edged sword. On the one hand, using social media actively helps individuals reduce stress, increases life satisfaction, reduces loneliness and enhances well-being [20-22]. Interacting with co-workers on social media after work promotes job satisfaction, as social media help employees keep their work tasks under control and bond with their colleagues [5]. Spending personal time on the Internet during work can help employees take a mental break and re-charge their batteries resulting in higher work engagement in the subsequent hour [6]. Taking a break from work using your smartphone was found to relate to higher levels of happiness by the end of the working day [23]. On the other hand, digital breaks from work were found to inhibit recovery [24], while extensive social media use at work results in lower work engagement [6]. Using Facebook passively (e.g., content consumption, without engagement or content creation) was related to lower life satisfaction and well-being [25]. Nevertheless, the association between social media and recovery experiences remains untangled.

Previous research has provided mixed results on the effect of social media use on recovery. These mixed findings may be due to the fact the previous studies mainly assessed the social media use. Hence, the present study focuses on the quality of the social media use instead, as experienced by the users. To this end, we investigated the role of emotion from actively engaging with the social media platform of Twitter at work and leisure. In this study, we employed the popular social networking micro-blogging service Twitter. Users share up to 280-character long text messages called tweets. Twitter attracts 321 million monthly users of all age groups [26], tweeting about various topics. The vast majority of users tweet about their lives on the go since $80 \%$ of them access the platform via their smartphone [27]. The advantages of Twitter, in terms of frequency of use, diversity of its population and speed of information, make it ideal for this study.

\section{The Moderating Role of Emotion from Twitter}

Social media in general, and Twitter in particular, offer a broad variety of services (e.g. networking, communication, content creation, etc.). By being active in Twitter, users may have variant experience and may satisfy different needs online (e.g. entertainment, information seeking, etc.). Thus, it is essential not to focus solely on social media use, but to examine what people are actually experiencing while using social media and how these experiences are affecting the recovery process. We argue that the emotion experienced while posting on Twitter at work and at leisure can moderate the 
impact of work exhaustion on recovery experiences. Emotion is an important component of everyday communication in both offline and online human interactions [28, 29]. Emotion can be described as "multi-component response tendencies that unfold over relatively short time spans" [30]. Compared to moods - which are more diffused and last longer - emotion is triggered by specific causes and has a limited duration [31]. Here, we adopt a two-dimensional structure composed of the orthogonal dimensions of positive and negative emotion [32].

Negative emotion refers to negative valence, such as distress and sadness. Research has shown that negative emotion narrows thought-action repertoires [33] and depletes individuals' personal resources [34] -a process detrimental to employee recovery [14]. Negative emotion also triggers reactivity. In this way, individuals' load reactions remain activated [8], which hampers exhausted employees from recovery experiences. Based on these arguments, we hypothesise:

Hypothesis 2: Negative emotion from tweets moderates the negative relationship between exhaustion and recovery experiences (i.e., psychological detachment and relaxation), where the relationship is stronger when negative emotion is high than when it is low.

Positive emotion refers to positive valence, such as happiness, alertness and excitement. Experiencing positive emotion broadens thought-action repertoires and helps employees build resources $[33,35,36]$. Positive emotion can down-regulate the negative impact of negative emotion on well-being [34]. Thus, when employees post tweets that elicit positive emotion, they gain resources that may help them counteract they negative impact of exhaustion on recovery experiences. Put differently, when exhausted employees experience higher (vs. lower) positive emotion by actively using Twitter, they are more likely to detach from work and relax because they gain resources that can be used for recovery purposes. Thus, we hypothesize:

Hypothesis 3: Positive emotion from tweets moderate the negative relationship between exhaustion and recovery experiences (i.e., psychological detachment and relaxation), where the relationship is weaker when positive emotion is high than when it is low.

\section{$5 \quad$ Method}

\subsection{Procedure and Sample}

A convenience sample was employed, consisted of full- and part-time employees that use Twitter. The participants completed an online questionnaire at the end of the working day, for a maximum of 5 working days. A bespoke system was built to retrieve the tweets employees posted. Participants reported their emotion about the tweets they posted on that day, together with questions about exhaustion at work, and psychological 
detachment and relaxation at leisure. Participation was voluntary and the data was gathered confidentially. As a participation incentive, respondents were offered to be included in a raffle for Amazon coupons at the end of the data collection.

The final study sample consisted of 33 employees ( $N=285$ study points), of which $16(48.5 \%)$ were women, and posting on average 3.4 tweets per day $(S D=1.5)$. Participants employed full-time were $97 \%$ of the sample, with mean tenure in their current position of 7 years $(S D=5)$. Their mean age was 38 years $(S D=8.4)$. The sample was heterogeneous in terms of jobs: 16 participants $(50 \%)$ were working in education, 6 $(18.8 \%)$ in technology and the rest were employed in sales, consulting, entertainment and administrative sectors. Their contract hours were on average 38 hours per week $(S D=7.5)$, while their actual working hours were on average 46 hours per week $(S D=$ 11). All participants held a university degree, with 15 (45.5\%) holding a master's degree, $11(33.3 \%)$ holding a $\mathrm{PhD}$ and 7 (21.2\%) a bachelor's degree.

\subsection{Measures}

The diary study assessed each participant's (positive and negative) emotion for different tweets they posted and their daily levels of exhaustion at work and psychological detachment and relaxation during leisure. Because of the demanding nature of diary studies [37] and to minimise participant burden, the variables were measured with the use of abbreviated and one-item scales [38].

Emotion from tweets. The momentary emotional experience elicited by each tweet was measured with items from the Positive and Negative Affect Schedule (PANAS) [32]. Participants were presented with a list of 8 PANAS descriptors (5 positive and 3 negative) and were asked to indicate the extent to which these adjectives described how they felt with regard to each tweet ("This tweet made me feel..."). All items were rated on a 5-point scale, ranging from (1) "not at all" to (5) "to a great extent". The items measuring positive emotion were 'happy', 'energetic', 'proud', 'interested' and 'attentive'. Cronbach's alphas ranged from .86 to .89 across the study points. The items measuring negative emotion were 'nervous', 'upset' and 'sad'. Mean Cronbach's alpha was $\alpha=.68$ (ranged from .55 to .76). Reliabilities for the emotion sub-scales were calculated on a tweet-basis (where reliability was measured for all the first tweets of the first day, then second tweets of the first day, etc.).

Daily work-related exhaustion. Two items from the Shirom-Melamed Burnout Measure (SMBM) were used to assess exhaustion: "Today at work, I felt exhausted" and "Today at work, I felt burned out". Items were scored on a 5-point scale ranging from (1) "totally disagree" to (5) "totally agree". The inter-item correlations ranged from .51 to .78 across the study days, suggesting high internal consistency.

Daily recovery experiences. Psychological detachment and relaxation were measured using items from the Recovery Experience Questionnaire [7], as adapted to measure daily recovery experiences [39]. Two items were used to measure psychological detachment: "during leisure, I forgot about work" and "during leisure, I didn't think about work at all." Inter-item correlations ranged from .66 to .96 across the study days. Relaxation was measured with the item: "after work, I used the time to relax". The items used for the purposes of this study were selected based on their factorial (Bakker et al., 
2015) and face validity. Response options were based on a 5-point scale, ranging from (1) "totally disagree" to (5) "totally agree".

\subsection{Strategy of Analysis}

Data were collected at the tweet-level $(N=285)$, the day-level $(N=5)$ and the personlevel $(N=33)$. Given that both antecedent and outcome variables were assessed at the day-level, and since we were interested in overall emotional experiences, data related to tweets (i.e., positive and negative emotions) were averaged to the day-level. Participants reported their emotion from tweeting for an average of 3.5 tweets per day $(\mathrm{min}=$ 1 ; $\max =6$ tweets/day). We tested a two-level model, with daily measurements (level1) nested in employees (level-2). All relationships were modelled at the within-person level of analysis. According to Maas and Hox's [40] rule of thumb, there is a need for at least 30 cases at the highest level of analysis in order to perform robust multilevel analyses with fixed slopes, making the sample of the study sufficient. Predictor and moderating variables were centred around the person mean, to capture within-person variations. The total sample was split into two samples based on the time the tweets were posted: one for the tweets posted at work $(N=32$ participants \& $N=95$ study points), and one for the tweets posted after work $(N=21$ participants $\& N=40$ study points). Hypotheses were tested for each sub-sample separately. Analyses were performed with MLwiN 3.00 [41]. For significant interaction effects, the simple slopes test was performed with the online calculation tool by Preacher, Curran and Bauer [42].

\section{Results}

\subsection{Preliminary Analyses and Descriptive Statistics}

First, we examined if the variance of the day-level dependent variables could be explained by both levels of analysis, by estimating the interclass correlation coefficient. Also, for each dependent variable a deviance difference test $\left(\Delta \chi^{2}\right)$ was conducted to test whether a model that accounted for two-levels (i.e., days nested in employees) fit the data better than a model with one level. Results indicated that the two-level model fit the data better than the one-level model, both for the sample for tweets posted at work and for the sample for tweets posted at leisure. For tweets posted at work, results showed that $57 \%$ of daily psychological detachment $(\Delta-2 \mathrm{x} \log =13.48, d f=1, p<.05)$ and $67 \%$ of daily relaxation $(\Delta-2 \mathrm{x} \log =8.84, d f=1, p<.05)$ could be attributed to within-person changes. For tweets posted during leisure, results showed that $22 \%$ of daily psychological detachment $(\Delta-2 \mathrm{x} \log =20.8, d f=1, p<.05)$ and $61 \%$ of daily relaxation $(\Delta-2 \mathrm{x} \log =4.42, d f=1, p<.05)$ is attributable to within-person changes, meaning that multilevel modeling is appropriate for testing the study hypotheses. The means, standard deviations, and correlations between the study variables for the tweets posted at work $(N=32$ participants $\& N=95$ study points $)$ and for the tweets posted at leisure $(N=21$ participants $\& N=40$ study points $)$ are presented in Table 1 . 
Table 1. Means, standard deviations and within-person correlations of the study variables for tweets at work and at leisure.

\begin{tabular}{|c|c|c|c|c|c|c|c|c|c|}
\hline Variables & $\begin{array}{l}\frac{y}{0} \\
\vdots \\
\vdots\end{array}$ & 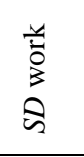 & $\frac{\mathscr{W}}{\stackrel{\Xi}{\Xi}}$ & 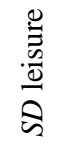 & 1 & 2 & 3 & 4 & 5 \\
\hline 1. Exhaustion & 2.41 & 1.10 & 2.39 & 1.20 & - & -.23 & .26 & -.05 & $-.46^{* *}$ \\
\hline 2. Positive emotions & 3.49 & 0.90 & 3.17 & 1.10 & -.13 & - & -.18 & -.02 & .14 \\
\hline 3. Negative emotions & 1.22 & 0.52 & 1.27 & 0.52 & -.01 & $-.25^{*}$ & - & -.20 & -.11 \\
\hline 4. Psychological detachment & 2.54 & 1.18 & 2.99 & 1.53 & -.10 & .20 & -.19 & - & $.48^{* *}$ \\
\hline 5. Relaxation & 3.01 & 1.20 & 3.00 & 1.43 & $-.44^{* *}$ & .19 & -.05 & $.47^{* *}$ & - \\
\hline \multicolumn{10}{|c|}{$\begin{array}{l}\text { Note. } N=32 \text { participants and } N=95 \text { study points for tweets posted at work. } N=21 \text { participants and } N=40 \\
\text { study points for tweets posted at leisure. Correlations above the diagonal concern tweets posted at leisure, and } \\
\text { below the diagonal concern tweets posted at work. The Mean and Standard Deviation for tweets at work and } \\
\text { tweets at leisure are also presented. ** } p<.01, * p<.05 \text {. }\end{array}$} \\
\hline
\end{tabular}

Table 2 presents the results from the multilevel analyses predicting psychological detachment, and Table 3 the multilevel analyses predicting relaxation. According to Hypothesis 1 , daily exhaustion was expected to relate negatively to both psychological detachment and relaxation. As shown in Tables 2 and 3, this hypothesis was rejected since no significant interaction found between exhaustion and the experiences of psychological detachment and relaxation.

According to Hypothesis 2, negative emotion from tweets was expected to boost the negative relationship between exhaustion and recovery experiences. Results regarding the negative emotion related to tweets during work did not support a significant interaction effect either on psychological detachment $(\beta=-0.25, \mathrm{SE}=0.43, t=-0.58, n s$; Table 2) or on relaxation ( $\beta=-0.18, \mathrm{SE}=0.46, t=-0.40, n s$; Table 3$)$. Also, results regarding negative emotion from tweets posted during leisure did not support the moderating role of negative emotion either on the relationship between exhaustion and psychological detachment $(\beta=0.20, \mathrm{SE}=1.09, t=0.18, n s$; Table 2$)$, nor on the relationship between exhaustion and relaxation $(\beta=0.35, \mathrm{SE}=1.13, t=0.31$, ns; Table 3$)$. Thus, Hypothesis 2 was rejected.

According to Hypothesis 3, positive emotion from tweets was expected to buffer the negative relationship between exhaustion and recovery experiences. Results showed that positive emotion from tweets posted during work indeed moderated the exhaustion - psychological detachment relationship $\left(\beta=0.63, S E=0.32, t=1.99^{* *}, p<.01\right.$; Table 2) significantly, but not the exhaustion - relaxation relationship $(\beta=0.07, S E=0.35, t$ $=0.19, n s$; Table 3). Results for the tweets posted during leisure did not support the moderating role of positive emotion from tweets either on the relationship between exhaustion and psychological detachment $(\beta=-0.88, S E=0.64, t=-1.38, n s$; Table 2$)$ or on the relationship between exhaustion and relaxation $(\beta=0.49, S E=0.76, t=0.65$, ns; Table 3). 


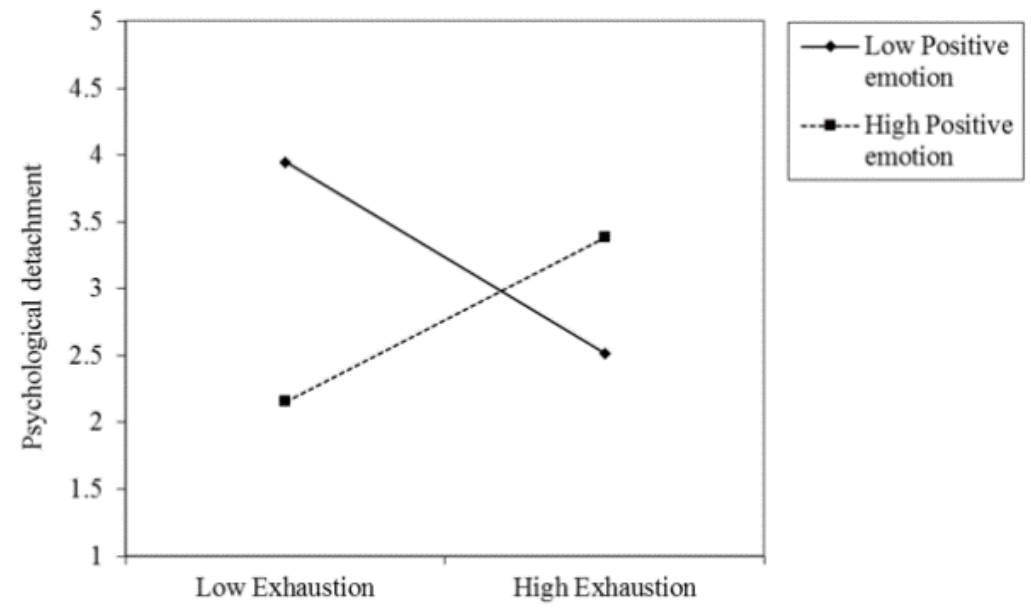

Fig. 1. Interaction effect of exhaustion and positive emotion from tweets on change in psychological detachment

We probed the significance of the simple slopes [42], to examine the pattern of the significant interaction effect of exhaustion and positive emotion on detachment. When positive emotion from tweets was low, exhaustion related negatively to detachment (estimate $=-2.27, S E=1.1, z=-2.07, p<.05$; Fig. 1), but was not related when positive emotion was high (estimate $=2.13, S E=1.13, z=-1.88, n s$; Fig 1 ), partially supporting Hypothesis 3.

Table 2. Multilevel analysis for day-level psychological detachment

\begin{tabular}{lrrr}
\hline Tweets posted during work & Est. & SE & $\mathrm{t}$ \\
\hline Intercept $(\gamma 0)$ & 2.60 & 0.17 & $15.49^{* *}$ \\
Exhaustion $(\gamma 1)$ & -0.07 & 0.14 & -0.49 \\
Positive emotions $(\gamma 2)$ & -0.28 & 0.22 & -1.27 \\
Exhaustion $\times$ Positive emotions $(\gamma 3)$ & 0.63 & 0.32 & $1.99^{* *}$ \\
Intercept $(\gamma 0)$ & 2.56 & 0.17 & $15.04 * *$ \\
Exhaustion $(\gamma 1)$ & -0.06 & 0.14 & -0.41 \\
Negative emotions $(\gamma 2)$ & -0.15 & 0.24 & -0.62 \\
Exhaustion $\times$ Negative emotions $(\gamma 3)$ & -0.25 & 0.43 & -0.58 \\
\hline Tweets posted during leisure & Est. & SE & $\mathrm{t}$ \\
\hline Intercept $(\gamma 0)$ & 2.89 & 0.32 & $9.10^{* *}$ \\
Exhaustion $(\gamma 1)$ & -0.09 & 0.15 & -0.61 \\
Positive emotions $(\gamma 2)$ & -0.05 & 0.33 & -0.15 \\
Exhaustion $\times$ Positive emotions $(\gamma 3)$ & -0.88 & 0.64 & -1.38 \\
Intercept $(\gamma 0)$ & 2.86 & 0.31 & $9.30^{* *}$ \\
Exhaustion $(\gamma 1)$ & -0.17 & 0.16 & -1.09 \\
Negative emotions $(\gamma 2)$ & 0.27 & 0.46 & 0.58 \\
Exhaustion $\times$ Negative emotions $(\gamma 3)$ & 0.20 & 1.09 & 0.18 \\
\hline Note. $N=32$ participants \& $N=95$ study points for tweets posted at work. $N=21$ participants \& $N=40$ study \\
points for tweets posted at leisure. $* * p<.01$ & & & \\
\hline
\end{tabular}


Table 3. Multilevel analysis for day-level relaxation

\begin{tabular}{lrrr}
\hline Tweets posted during work & Est. & SE & $\mathrm{t}$ \\
\hline Intercept $(\gamma 0)$ & 3.04 & 0.17 & $18.34^{* *}$ \\
Exhaustion $(\gamma 1)$ & -0.28 & 0.15 & -1.82 \\
Positive emotions $(\gamma 2)$ & -0.23 & 0.25 & -0.92 \\
Exhaustion $\times$ Positive emotions $(\gamma 3)$ & 0.07 & 0.35 & 0.19 \\
Intercept $(\gamma 0)$ & 3.04 & 0.16 & $18.64^{* *}$ \\
Exhaustion $(\gamma 1)$ & -0.23 & 0.15 & -1.50 \\
Negative emotions $(\gamma 2)$ & -0.02 & 0.26 & -0.08 \\
Exhaustion $\times$ Negative emotions $(\gamma 3)$ & -0.18 & 0.46 & -0.40 \\
\hline Tweets posted during leisure & Est. & SE & $\mathrm{t}$ \\
\hline Intercept $(\gamma 0)$ & 3.00 & 0.25 & $11.87^{* *}$ \\
Exhaustion $(\gamma 1)$ & -0.71 & 0.21 & $-3.43^{* *}$ \\
Positive emotions $(\gamma 2)$ & -0.38 & 0.45 & -0.86 \\
Exhaustion $\times$ Positive emotions $(\gamma 3)$ & 0.49 & 0.76 & 0.65 \\
Intercept $(\gamma 0)$ & 3.02 & 0.26 & $11.69^{* *}$ \\
Exhaustion $(\gamma 1)$ & -0.68 & 0.20 & $-3.44 * *$ \\
Negative emotions $(\gamma 2)$ & -0.24 & 0.58 & -0.41 \\
Exhaustion $\times$ Negative emotions $(\gamma 3)$ & 0.35 & 1.13 & 0.31 \\
\hline Note. $N=32$ participants \& $N=95$ study points for tweets posted at work. $N=21$ participants \& $N=40$ \\
study points, for tweets posted at leisure. ** $p<.01$ & & & \\
\hline
\end{tabular}

\section{$7 \quad$ Discussion, Implications and Future Research}

In this diary study, we examined the moderating role of positive and negative emotion elicited from tweets (during and after work) on the relationship between daily workrelated exhaustion and the recovery experiences of psychological detachment and relaxation during leisure. In contrast to our expectations, daily exhaustion from work was not found to associate directly to psychological detachment or relaxation. However, multilevel analyses showed that the positive emotion elicited by the social media activity moderated the recovery process. As expected, in line with the broaden-and-build theory [33, 43], when employees are experiencing positive emotion when posting on Twitter, the negative impact of exhaustion on psychological detachment from work is buffered. Contrary to expectations, positive emotion elicited from tweeting were not found to buffer the impact of exhaustion on relaxation, while negative emotion did not significantly strengthen the negative impact of exhaustion on recovery experiences.

The study contributes to the literature, by providing a better understanding of the exhaustion - recovery experiences relationship when taking into consideration the emotional experiences in the social media context. Our results contribute to the discussion on the impact of social media on recovery from work, by showing that the quality of the social media activity and specifically the experience of positive emotion is relevant for the recovery process. Taking into consideration that recovery is crucial for healthy and productive employees that help organisations flourish, understanding recovery when using social media has also practical implications. Organisations can allow social media use at work, as it can buffer the negative impact of job demands on employees. As research has shown, recovery can be supported by intervention programmes [44]. 
Work trainings could include the topic of social media use at work to help employees reflect on their use and benefit from it on the level of recovery and well-being.

Our study has some limitations. First, the study does not comprise an exhaustive framework for all potential factors that may determine the social media-recovery relationship. Future research could replicate the study, while introducing new factors, to shed more light on the impact of social media on recovery. One such is examining the effects discrete emotions may have on recovery. Next, the sample size was relatively small. While the sample size was adequate for the purposes of the study [40], future research can benefit from larger sample sizes. Finally, this study was conducted in the Twitter setting, excluding other social media. This may place constraints to the generalisability of the findings. However, the study did not focus on Twitter use per se, but on the quality of experience when using Twitter. Future research could replicate our framework by adopting other social media. To conclude, the quality of social media experience can have an impact on the job demands-recovery relationship. Future research is needed to focus on the quality of social media experience and its implication on employee well-being.

\section{References}

1. Demerouti, E., Bakker, A.B., Geurts, S.A., Taris, T.W.: Daily recovery from work-related effort during non-work time. Current perspectives on job-stress recovery, pp. 85-123. Emerald Group Publishing Limited (2009)

2. Sonnentag, S., Arbeus, H., Mahn, C., Fritz, C.: Exhaustion and lack of psychological detachment from work during off-job time: Moderator effects of time pressure and leisure experiences. J Occup Health Psych 19(2), 206-216 (2014).

3. Derks, D., Bakker, A.B.: Smartphone Use, Work-Home Interference, and Burnout: A Diary Study on the Role of Recovery. Appl Psychol-Int Rev 63(3), 411-440 (2014).

4. Quinones, C., Griffiths, M.D.: The impact of daily emotional demands, job resources and emotional effort on intensive internet use during and after work. Computers in Human Behavior 76(C), 561-575 (2017).

5. Robertson, B.W., Kee, K.F.: Social media at work: The roles of job satisfaction, employment status, and Facebook use with co-workers. Computers in Human Behavior 70, 191-196 (2017).

6. Syrek, C.J., Kühnel, J., Vahle-Hinz, T., De Bloom, J.: Share, like, twitter, and connect: Ecological momentary assessment to examine the relationship between non-work social media use at work and work engagement. Work \& Stress 32(3), 209-227 (2018).

7. Sonnentag, S., Fritz, C.: The recovery experience questionnaire: Development and validation of a measure for assessing recuperation and unwinding from work. J Occup Health Psych 12(3), 204-221 (2007).

8. Meijman, T.F., Mulder, G.: Psychological aspects of workload. Handbook of Work and Organizational Psychology. Volume 2, (1998).

9. Xanthopoulou, D., Meier, L.L.: 5 Daily burnout experiences. Burnout at work: A psychological perspective, 80 (2014). 
10. Sonnentag, S.: Work, recovery activities, and individual well-being: a diary study. J Occup Health Psych 6(3), 196 (2001).

11. Oerlemans, W.G.M., Bakker, A.B.: Burnout and Daily Recovery: A Day Reconstruction Study. J Occup Health Psych 19(3), 303-314 (2014).

12. ten Brummelhuis, L.L., Trougakos, J.P.: The recovery potential of intrinsically versus extrinsically motivated off-job activities. J Occup Organ Psych 87(1), 177-199 (2014).

13. Sonnentag, S., Zijlstra, F.R.H.: Job characteristics and off-job activities as predictors of need for recovery, well-being, and fatigue. J Appl Psychol 91(2), 330-350 (2006).

14. Hobfoll, S.E.: Conservation of resources: A new attempt at conceptualizing stress. American psychologist 44(3), 513 (1989).

15. Taris, T.W.: Is there a relationship between burnout and objective performance? A critical review of 16 studies. Work \& Stress 20(4), 316-334 (2006).

16. Peterson, U., Demerouti, E., Bergström, G., Åsberg, M., Nygren, Å.: Work characteristics and sickness absence in burnout and nonburnout groups: A study of Swedish health care workers. Int J Stress Manage 15(2), 153 (2008).

17. ten Brummelhuis, L.L., Bakker, A.B.: A resource perspective on the work-home interface: The work-home resources model. American Psychologist 67(7), 545 (2012).

18. McCay-Peet, L., Quan-Haase, A.: What is Social Media and What Questions Can Social Media Research Help Us Answer? The SAGE Handbook of Social Media Research Methods, 13 (2017).

19. https://blog.globalwebindex.net/chart-of-the-day/daily-time-spent-on-social-networks/

20. van Ingen, E., Rains, S.A., Wright, K.B.: Does social network site use buffer against wellbeing loss when older adults face reduced functional ability? Computers in Human Behavior 70, 168-177 (2017).

21. Wang, J.-L., Jackson, L.A., Gaskin, J., Wang, H.-Z.: The effects of Social Networking Site (SNS) use on college students' friendship and well-being. Computers in Human Behavior 37, 229-236 (2014).

22. Matook, S., Cummings, J., Bala, H.: Are you feeling lonely? The impact of relationship characteristics and online social network features on loneliness. Journal of Management Information Systems 31(4), 278-310 (2015).

23. Rhee, H., Kim, S.: Effects of breaks on regaining vitality at work: An empirical comparison of 'conventional'and 'smart phone'breaks. Computers in Human Behavior 57, 160-167 (2016).

24. Kim, S., Park, Y., Niu, Q.: Micro-break activities at work to recover from daily work demands. J Organ Behav 38(1), 28-44 (2017).

25. Wenninger, H., Krasnova, H., Buxmann, P.: Activity matters: Investigating the influence of Facebook on life satisfaction of teenage users. (2014).

26. https://s22.q4cdn.com/826641620/files/doc_financials/2018/q4/Q4-2018-SelectedCompany-Financials-and-Metrics.pdf

27. Wang, W., Hernandez, I., Newman, D.A., He, J., Bian, J.: Twitter Analysis: Studying US Weekly Trends in Work Stress and Emotion. Applied Psychology: An International Review 65(2), 355-378 (2016).

28. Derks, D., Fischer, A.H., Bos, A.E.: The role of emotion in computer-mediated communication: A review. Computers in human behavior 24(3), 766-785 (2008). 
29. Pappas, I.O., Kourouthanassis, P.E., Giannakos, M.N., Chrissikopoulos, V.: Shiny happy people buying: the role of emotions on personalized e-shopping. Electronic Markets 24(3), 193-206 (2014).

30. Fredrickson, B.L.: The broaden-and-build theory of positive emotions. Philosophical Transactions of the Royal Society B: Biological Sciences 359(1449), 1367 (2004).

31. Gray, E.K., Watson, D., Payne, R., Cooper, C.: Emotion, mood, and temperament: Similarities, differences, and a synthesis. Emotions at work: Theory, research and applications for management, 21-43 (2001).

32. Watson, D., Clark, L.A., Tellegen, A.: Development and Validation of Brief Measures of Positive and Negative Affect: The PANAS Scales. Journal of Personality and Social Psychology 54(6), 1063-1070 (1988).

33. Fredrickson, B.L.: The role of positive emotions in positive psychology: The broaden-andbuild theory of positive emotions. American psychologist 56(3), 218 (2001).

34. Fredrickson, B.L., Mancuso, R.A., Branigan, C., Tugade, M.M.: The undoing effect of positive emotions. Motivation and emotion 24(4), 237-258 (2000).

35. Fredrickson, B.L., Levenson, R.W.: Positive emotions speed recovery from the cardiovascular sequelae of negative emotions. Cognition \& emotion 12(2), 191-220 (1998).

36. Xanthopoulou, D., Bakker, A.B., Demerouti, E., Schaufeli, W.B.: A diary study on the happy worker: How job resources relate to positive emotions and personal resources. European Journal of Work and Organizational Psychology 21(4), 489-517 (2012).

37. Bolger, N., Davis, A., Rafaeli, E.: Diary methods: Capturing life as it is lived. Annual review of psychology 54(1), 579-616 (2003).

38. Ohly, S., Sonnentag, S., Niessen, C., Zapf, D.: Diary studies in organizational research. Journal of Personnel Psychology, (2010).

39. Bakker, A.B., Sanz-Vergel, A.I., Rodríguez-Muñoz, A., Oerlemans, W.G.M.: The state version of the recovery experience questionnaire: A multilevel confirmatory factor analysis. European Journal of Work \& Organizational Psychology 24(3), 350-359 (2015).

40. Maas, C.J., Hox, J.J.: Sufficient sample sizes for multilevel modeling. Methodology 1(3), 86$92(2005)$.

41. Charlton, C., Rasbash, J., Browne, W., Healy, M., Cameron, B.: MLwiN Version 3.00. Bristol: Centre for Multilevel, Modelling University of Bristol, (2017).

42. Preacher, K.J., Curran, P.J., Bauer, D.J.: Computational tools for probing interactions in multiple linear regression, multilevel modeling, and latent curve analysis. Journal of educational and behavioral statistics 31(4), 437-448 (2006).

43. Weiss, H.M., Cropanzano, R.: Affective events theory: A theoretical discussion of the structure, causes and consequences of affective experiences at work. (1996).

44. Querstret, D., Cropley, M., Fife-Schaw, C.: Internet-based instructor-led mindfulness for work-related rumination, fatigue, and sleep: Assessing facets of mindfulness as mechanisms of change. A randomized waitlist control trial. J Occup Health Psych 22(2), 153 (2017). 